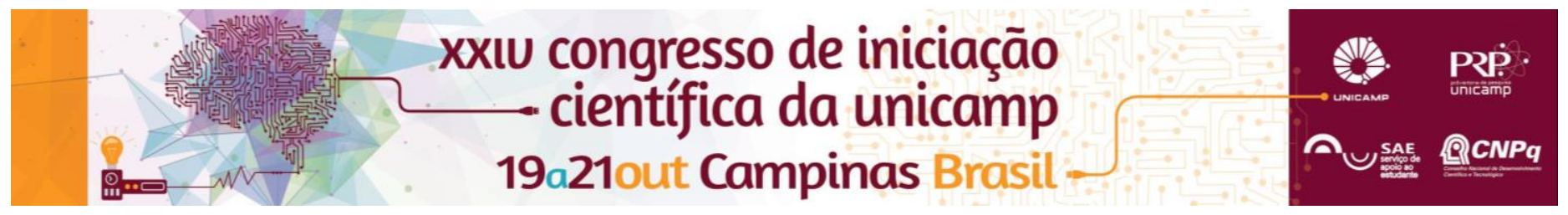

\title{
Estudo fotofísico de um copolímero contendo fluoreno e bipiridina utilizando diferentes proporções de complexos de Európio (III) coordenados à cadeia principal.
}

\section{Matheus G. Setter.}

\section{Resumo}

Este projeto de iniciação científica tem por objetivo o estudo fotofísico de um derivado de polifluoreno- o poli[9,9'dihexilfluoreno-diil-alt-3,5-bipiridinevinileno] complexado com Európio, pretendendo-se verificar a quantidade mínima necessária de európio complexado à cadeia polimérica para que o material mantenha as propriedades apresentadas em trabalhos anteriores, nos quais verificou-se que a proporção $1: 1 \mathrm{~mol} / \mathrm{mol}$ o confere propriedades termocrômicas.

\section{Palavras-chave:}

Semicondutores orgânicos, eletroluminescência, fotofísica.

\section{Introdução}

A pesquisa de novos materiais funcionais com aplicações específicas, baixo custo e simplicidade de manufatura é a busca principal na área de ciência dos materiais. Neste campo de opto-eletrônica os mostradores para iluminação, células fotovoltáicas, e sensores de temperatura são particularmente relevantes. Neste contexto, sistemas poliméricos contendo íons metálicos tem sido o foco de atenção porque eles podem combinar as propriedades fotofísicas do metal com aquelas dos polímeros, como a capacidade de formação de filmes e processabilidade pelas técnicas de "spin-coating", "jet printing", "casting" entre outras.

Essa classe de materiais tem sido classificada como metalopolímeros, na qual o metal é ligado diretamente na cadeia polimérica ou na cadeia lateral. Metais terras raras, especificamente os lantanídeos, mostram uma alta emissão de luminescência, com bandas de emissão estreitas. Além do processo de fotoemissão, existem vários casos relatados de termocromismo de terras raras dispersas em matrizes de polímero, mas situações em que os componentes metálicos estão quimicamente ligados a um polímero conjugado estão ainda em fase inicial. Dados recentes mostraram que os níveis de energia do estado excitado dos íons Ln3+ são altamente sensíveis à temperatura, e que esta propriedade pode ser explorada em sensores de temperatura, usando Tb3 +, Eu3 + e seus complexos.

Neste projeto, propriedades fotofísicas, do sistema poli[9,9'-dihexilfluoreno-diil-alt-3,5-bipiridinevinileno] e seu complexo com íon európio será estudado, variando-se as proporções de polímero-Eu.

\section{Resultados e Discussão}

Os materiais LAPPS34Eu- A e $C$, seguiram as características do LAPPS34 Eu já estudado anteriormente, sendo 0 artigo que apresenta estes resultados utilizado como parâmetro para avaliar estes novos materiais. Assim, como realizado ateriormente, obtve-se tanto para o polímero quanto para o európio os espectros de absorção, emissão a temperatura ambiente e com variações de temperatura e o tempo de vida com variações de temperatura. Todas as medidas foram obtidas com uma solução $10^{-3} \mathrm{~mol} / \mathrm{L}$ do material em THF, com exceção das medidas de emissão do polímero, que foram realizadas com solução $10^{-5} \mathrm{~mol} / \mathrm{L}$ do material.

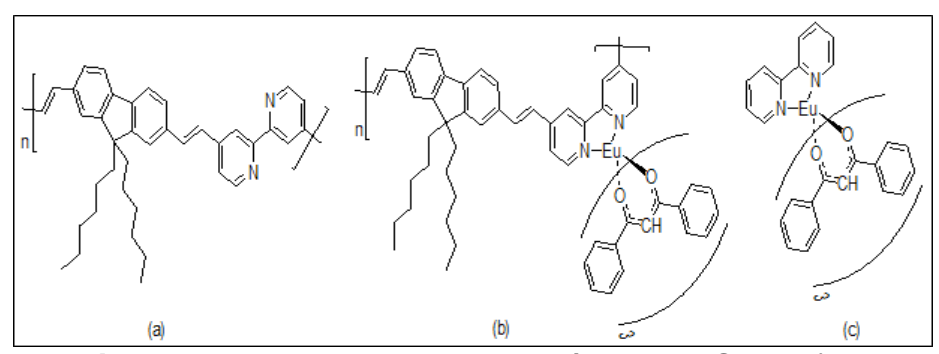

Figura 1: Estrutura do: a) LAPPS34 (ligante polifluoreno); b) LAPPS34Eu (Complexo de polifluoreno e európio com $80 \%$ de Európio); c) LAPPS34M ( Complexo de Európio e bipiridina).
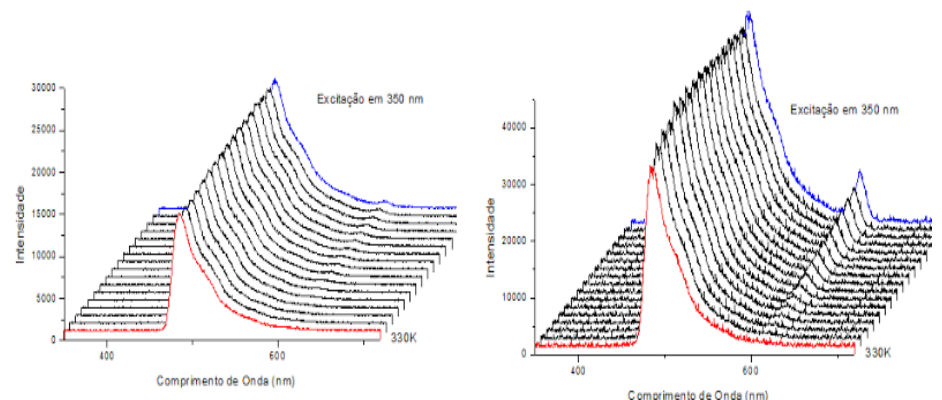

Figura 2: Espectros de emissão em solução de THF, 10-3 mol/L, em função da temperatura, 170K - 330K, com excitação em 350 nm. a) L34-A (25\%), b) L34-C (70\%).

\section{Conclusões}

O estudo do LAPPS34EU - A e C, mostraram que a diminuição da quantidade de metal no complexo, neste caso o mínimo de $25 \%$ no LAPPS $34-A$, ainda confere ao material as mesmas características do material com $80 \%$ de Európio.

\section{Agradecimentos}

Agradeço a minha co-orientadora Raquel Domingues, a prof. Teresa Atvars, ao Denis Turchetti, aos alunos de Doutorado José Carlos Germino e Luís Duarte e ao técnico do laboratório Dr. Marcelo Faleiros.

Denis A. Turchetti, Raquel A. Domingues, Cristiano Zanlorenzi, Bruno Nowacki, Teresa D. Z. Atvars, and Leni C. Akcelrud

The Journal of Physical Chemistry C 2014118 (51), 30079-30086 ${ }^{1}$ Curtis, M. D.; Shiu, K.; Butler, W. M. e Huffmann, J. C. J. Am. Chem. Soc. 1986, 108,3335 . 